\title{
El rito del trato de compra-venta del pimentón en Murcia
}

Desde la Antigüedad, en que se ideó la función de la moneda - un vehículo de transmisión dotado de un valor que la convertía de realidad abstracta en un medio válido de intercambio, en un objeto precioso-, se fue haciendo realidad la posibilidad de que se desarrollasen las relaciones materiales que se establecían entre los hombres sobre lo que se entendió como tráfico comercial. Una acción de compraventa, por la que una persona, que aparecía como dadora o vendedora, ofrecía y entregaba a otra persona, receptora o compradora, que correspondía con moneda (en lo que era visto como un acto de reciprocidad), una cosa o la realización de un servicio que a su vez habían sido tasados en su precio con la mayor precisión posible. Desde ese momento, las relaciones humanas cambiaron para configurar una nueva cultura en la que se establecía la posibilidad de actuación de los hombres, guiados por un interés lucrativo que se denominó beneficio y que, a su vez, tuvo como consecuencia inmediata que se pasasen a argumentar diferencias cuantitativas que se reflejaron, también, en otras cualitativas, o por lo menos así fueron tenidas. Desde ese punto, las relaciones de intercambio comercial, que vinieron a sustituir a las de mero trueque natural, mucho más indefinidas y aleatorias, y sobre todo mucho más limitadas en las posibilidades de lo que habría de llamarse desarrollo económico, pasaron a ser la llave mágica que ordenó la actuación de los hombres y de los pueblos en múltiples vías, a la vez que otorgaba poder y reconocimiento.

Pero la idea de valor es un principio que actúa de manera harto diferente en los desiguales componentes que intervienen en el acto de intercambio comercial, pues por un lado está la moneda, que aparece siempre como fruto de una tasación objetiva, y por otro, frente a ella, la cosa o el servicio que se transfieren, y cuyo valor es consecuencia de un cálculo subjetivo en el que entran en juego los más diversos factores, entre ellos, y con gran presencia, los personales. A su vez, las consecuencias de la presencia de ambas caracterizaciones en el momento de la transación comercial, además, están mediatizadas por la presencia de las fuerzas que intervienen en esa acción como son, en un platillo de la balanza, las que impulsan a la idea de remuneración y beneficio sobre el costo, que no 
es fijo ni en cantidad ni en porcentaje, y que de manera inmediata se contrarrestan con la de pérdida o sobrecosto, en el otro.

Todo ello conlleva una complejidad que se manifiesta con completa intensidad en el momento en que se materializa el acto del ritual del trato por el que las dos partes, en un principio opuestas, tratan de hacer realidad la operación comercial que se intenta llevar a feliz término, siempre dentro de un equilibrio compensatorio que permita que, tanto el comprador como el vendedor, a partir del momento en que se acepta el precio que la termina, adquieran conciencia de que se ha alcanzado el punto equidistante que la hace justa y equitativa.

Pero este ritual del trato, en sí mismo puede presentarse como la culminación de una larga operación de tanteo dentro de posturas de alejamiento y aproximación, en realidad, es el principio de una larga serie de obligaciones que desde ese instante pesan sobre las partes y que culminan con el pago completo de la mercancía que fue entregada conforme a las condiciones estipuladas, y como tal ha tenido a lo largo de la historia del comercio una enorme cantidad de variantes. Fiel reflejo de las sociedades en que se ha llevado a cabo, y que poco a poco han ido remitiendo y uniformándose conforme se han ido imponiendo las formulaciones diseñadas por las leyes comerciales de cada país, que, a su vez, servían de base y documento legal sobre el que se podían determinar las consecuencias en caso de incumplimiento por alguna de las partes.

Por ello, el rito del trato tiene un valor en sí mismo, porque nos habla de unas relaciones y unas circunstancias que dominan en cada momento, y como tal debe ser analizado. El mejor camino que se puede seguir, en una justa apreciación y perspectiva, es describirlo conforme se desarrolla en determinadas áreas, independientemente de las variantes que pueden darse en otras, aledañas o remotas, que, por otro lado, completarían un conocimiento etnográfico del mismo. En este sentido, podemos aproximarnos a un caso concreto como es el del campesino murciano, que ha producido, dentro de una tradición de cultivos, tanto en la huerta como en tierras de secano, una larga serie de frutos que han tenido diferentes encauzamientos comerciales: el directo, en el mercado de los jueves de la ciudad de Murcia, en el que no hay mediadores que interfieran y en el que el productor vendió y vende, sobre todo, productos perecederos sobre el precio que se estipula por los que concurren a él, conforme a una demanda más o menos definida; o el indirecto, que va a parar a la industria y cuya venta queda fijada dentro de unas reglas completamente distintas y en las que el rito del trato marca la pauta que se puede seguir.

Uno de los géneros que pueden servirnos para describir dicho ritual es el del pimiento seco o cáscara de pimentón. Producto que se obtiene 
después de una elaboración de desecado del pimiento, del tipo capsicum annum, de forma pequeña y redondeada, que porta una gran concentración de pigmento rojo y que, una vez molturado con la semilla o binza, según diversas proporciones, da el pimentón molido, especie colorante y aromática muy apreciada, en sus diversas calidades. El pimiento es uno de los frutos que encontraron los españoles en América cuando buscaban la pimienta negra que se producía en las Indias Orientales. Como curiosidad botánica y nuevo producto comestible lo trajo Cristobal Colón en uno de sus viajes ${ }^{1}$. El pimiento para pimentón, como una variedad específica, se cultivó por primera vez en España en Extremadura, de donde pasó a Murcia cuando los frailes de la Orden de San Jerónimo, a finales del siglo XVII, ocuparon las tierras que les fueron donadas en el pequeño poblado de La Ñora, y en las que en los primeros años del siglo siguiente levantaron monasterio, lo que a su vez llevó a que este tipo de pimiento, debidamente seco, recibiera el nombre de ñora, denominación que en la actualidad se da al que se seca sin llegar a romperse y es cosido por el rabo en ristras. En el siglo XVIII se generalizó su cultivo por toda la huerta del Segura, y en los molinos de agua que había en sus acequias ya se produjo pimentón que después, como se desprende de la lista y precios de productos que se registraban en las Actas Capitulares, traían para su venta en la ciudad los huertanos ${ }^{2}$. Éstos a su vez, por medio de arrieros, lo llevaron a todas las regiones españolas, pasando a ser un ingrediente imprescindible en la fabricación de determinados embutidos y comidas. En los siglos XIX y xx su cultivo pasó a tierras de secano conforme se fue posibilitando el riego con las aguas subterráneas.

La producción del pimiento siempre ha sido laboriosa, por las múltiples y delicadas faenas que requería desde que se iniciaba su siembra en los planteles o almajaras durante el mes de febrero. Su transplante a los bancales de cultivo, debidamente abonados y acaballonados se efectuaba en abril y mayo. Una vez agarradas y desarrolladas las raíces nuevas, exigía cuidados como levantarles la tierra, dar los riegos necesarios tras vencer la escasez del agua..., aparte de sortear el riesgo de los fríos que podían presentarse en plena floración. Por último, cuando, a finales de agosto o comienzos de septiembre, el fruto estaba maduro, lo que venía marcado por la intensidad de su color rojo granate, se iniciaba la penosa recolección para, una vez abiertos a mano uno por uno, extenderlos en las eras durante dos o tres días para su secado al sol, mientras se permanecía con la vista atenta a las nubes que pasaban por el cielo y que amenazaban

1 Frederic Rosengarten, Jr., The book of spices (Philadelphia, 1969), p. 130.

2 Archivo Municipal de Murcia, Actas Capitulares de los años 1760 a 1800. 
descargar las lluvias de otoño, menguadas pero suficientes para arruinar la cosecha en el momento de recogerla. Ésta se guardaba en las habitaciones que hacían de almacén en el caserío, las salas, donde quedaría a disposición de los compradores para su ojeo y examen de la calidad.

La venta de un producto como la cáscara de pimentón durante la primera parte del siglo xx siguió por parte del campesino dos caminos: uno, sobre todo en la Huerta —que entonces era donde se producía la mayor cantidad-, ofreciéndosela a los fabricantes que ya recibían el sobrenombre de exportadores, aunque sólo lo fuesen en un pequeño número, y que lo compraban por carros aunque ello no marcase una determinada cantidad, ya que se pesaba por arrobas en romana, de dos en dos sacos, y destaraba seguidamente, a la puerta del caserío. Otros la llevaban a los molinos de la ciudad o los que había en la huerta donde se molía para ofrecerla debidamente transformada como pimentón.

En la década de los cincuenta se inició un alza en el comercio del pimentón, sobre todo con la exportación a Estados Unidos, que conllevó que las tradicionales plantaciones que habían venido haciéndose en la Huerta de Murcia, muy limitadas, resultaran insuficientes ante la continuada y creciente demanda, lo que hizo que se dispusieran tierras en régimen de arriendo, principalmente en los campos de Totana, Alhama y Campo de Cartagena, para llevar a cabo plantaciones en gran escala, favorecidas porque las aguas de los riegos tradicionales se vieron enriquecidas con los aportes de aguas fósiles del subsuelo que se comenzaron a extraer en los pozos artesianos por medio de bombas eléctricas. Con esto el pimiento para pimentón pasó a ser cultivado en extensiones que poco a poco se fueron haciendo más amplias, con el consiguiente aumento de cantidades de trabajo, gastos, capital en juego y riesgos, lo que condujo a que quedase en manos de grandes productores, aunque nunca faltaron los que continuaron haciéndolo a pequeña escala.

El paso de la comercialización de este producto entre agricultor y fabricante llegó así a realizarse sobre un entramado aparentemente simple en el que la figura del intermediario o corredor sufrió un cambio sustancial, ya que si anteriormente este hombre jugaba el papel de enlazar al agricultor -fijo en su caserío, presentando sus muestras de los montones de cáscara y sus pretensiones de precio- con el fabricante, fijo en su molino y almacén, y receptivo o no a efectuar la compra, ahora el papel de trajinero se hacía más complejo, ya que su trabajo tenía que hacerse sobre presupuestos diferentes. De mero presentador de muestras representativas, y de un precio que admitía contraoferta, pasaba a desempeñar un papel activo y decisivo para que las partes llegasen a un acuerdo. Antes se había tenido que labrar la senda que le llevaba a merecer la confianza 
plena de ambos, lo que conllevaba que todo el negocio descansase sobre esa confianza, y que por ello fuese clave en las actuaciones que conformaban el trato. Su trabajo era compensado con una comisión, el 3 por 100 por parte del vendedor, y una cantidad alzada por kilogramos adquiridos, que podía variar, por parte del comprador, siendo sus obligaciones, aparte de ir y venir entre las partes para llegar a un buen fin en la operación de compra-venta, las de correr con los gastos del envasado y carga al camión, aunque no del transporte, puesto que siempre era la parte compradora la que habilitaba los medios necesarios.

Pero antes de llegar al trato propiamente dicho, al rito del trato de compra-venta, había una larga serie de relaciones personales que mediaban en los meses anteriores y que comenzaban con las visitas que el corredor efectuaba de manera repetida tanto al agricultor, para interesarse por el desarrollo de la plantación y a la vez promediar la cantidad que podría alcanzar el fruto, como al exportador, para informarle de cómo iban las cosas en el campo. Así demostraba su ascendencia sobre determinados productores que eran, a su vez, los que actuaban con mayor seriedad, y siempre con el fin de ganarse la confianza y establecer una relación de compromiso con ambas partes dentro de una amistad interesada, para que al final, cuando llegase el momento, uno le confiase la venta, porque le respaldaba una casa o fabricante con toda clase de seriedad comercial y garantías en el pago (si es que este se estipulaba que se haría en varias veces), y otro le diese suficientes órdenes de compra que le permitiesen cumplir con su cometido, con su consiguiente remuneración.

Verdaderamente, la figura del corredor descansaba en la confianza que era capaz de transmitir en este juego de intereses que, además, aparecía dentro de una configuración que no era meramente coyuntural, sino de largo plazo. El campesino sabía que su producto y con él su trabajo y dinero empleado, en cierta forma, dependían de cómo obrase este hombre, ya que unas veces, por presentarse una cosecha copiosa, podía necesitar de él para que la cáscara saliese en el momento oportuno de precio y tiempo camino de la fábrica y no corriese el peligro de ver cómo ésta quedaba sin que nadie se interesase. Otras veces, por ser la cosecha escasa, le aconsejaría que se mantuviese firme en la defensa de un precio durante algún tiempo. Por la otra parte sucedía lo mismo, aunque sobre intereses opuestos.

Frente a esta dependencia del campesino y el fabricante respecto al corredor, tanto uno como otro procuraban tener relaciones, aunque de manera un tanto encubiertas, con otros intermediarios que manifestaban en momentos oportunos, en demostración de una libertad de acción que ellos mismos procuraban restringir a unos justos términos. 
El trato propiamente dicho comenzaba cuando una de las dos partes daba muestras de querer vender, o daba órdenes de compra, que siempre procuraban ser muy concretas en cuanto a la zona y precio. Entonces el corredor se llegaba hasta el caserío para encontrarse con el campesino -que salvo en día de mercado, estaba siempre en él-y sin demostrar ninguna prisa iniciaba una información de cómo estaban las cosas, de los contratos de exportación que él sabía que había hechos, de las cantidades que se calculaban en otras comarcas, la calidad de aquel año, en la zona, de la cáscara que ya estaba molturada; las garantías que ofrecían los compradores que él ofertaba... Por su parte, el campesino en las tardes anteriores había hecho averiguaciones de manera más o menos velada, ya que se tenía a gala no preguntar a los vecinos el precio al que habían vendido o al que pretendían vender, entre otras cosas porque se contaba con la seguridad de que contestarían con mentiras, vaguedades y muestras de ignorancia, del tipo de: que no sabía, que todavía no se había becho una idea aproximada de cómo estaban las cosas esa temporada...

La norma que conducía el trato era que ninguna de las partes que intervenían podía hacer demostraciones de lo que sabía, aunque el corredor tuviera que obrar con una tensa cautela y una sobreentendida astucia para que nunca le pudieran decir que, por querer que se hiciese la operación con su beneficio, había equivocado a alguien; pues su fuerza radicaba en que se propalase su fama de hombre eficaz en aquel trabajo, de hombre que actuaba con seriedad - la primera y principal virtud en las relaciones comerciales-, de lo contrario ésta sufriría un deterioro que le llevaría a un apartamiento del que difícilmente podría salir. Al industrial, aparte de los datos y detalles referentes a la calidad, debería informarle de la situación personal en que se encontraba el campesino y de las posibilidades que había para conseguir que cediese en alguna cantidad del precio fijado por el mercado si se presentaba la ocasión durante el trato, bien porque se le pudiese ofrecer algún adelanto de dinero antes de retirar la mercancía, o por otro motivo. Al agricultor, además de lo apuntado, debería facilitarle los precios a los que había vendido algún vecino para ver si existía la posibilidad de vender algo más caro, aunque fuese una cantidad mínima, con lo que conseguiría marcar una diferencia en su calidad de productor y de vendedor respecto a los productores de su entorno. Ello le daría ocasión de demostrar, cuando se presentase el momento, un valer más a través de ironías y comentarios, o de medias palabras que transmitían el mensaje, en lo que su mujer no se quedaría a la zaga.

El trato venía a convertirse en una especie de arte que en primer lugar administraba el tiempo. Nadie debía precipitarse, aunque las posibilidades iniciales pareciesen irreconciliables por sus pretensiones. Cuando la can- 
tidad de dinero que mediaba era considerable, las razones que argumentaba cada postura debían de repetirse una y otra vez, aunque siempre con pequeños cambios y matices que posibilitaban el avance hacia una cifra posible para ambas partes, y que, con frecuencia, era el precio que se consideraba que corría normalmente en el mercado. El agricultor, así defendía su trabajo y una cáscara que era la mejor que se cosechaba, y el fabricante, desde su molino, procuraba comprar bien para poder competir en el mercado. Cuando alguna de las partes se mostraba irreductible en una buena fase del trato, era señal de que éste debía romperse sin ninguna clase de compromiso ulterior por ninguna de las partes. El trato, así entendido, debía de durar un tiempo determinado que, por lo general, comprendía varios días, lo que permitía que el corredor consultase una o varias veces con el industrial para ver el interés que tenía en aquella partida de cáscara y la posibilidad de ceder hasta alcanzar determinada cantidad. El campesino, por su parte, divulgaría en su medio que estaba en trato con determinada casa comercial, que pensaba mantenerse firme en su propuesta, y, sobre todo - $\mathrm{y}$ esto entraba en lo privado-, mientras tanto consultaría con su mujer, oiría sus razones, hasta que ésta le diese su consentimiento que el mayor número de veces era decisivo para llegar al final. De esta manera, al día siguiente, el trato se reanudaba en el punto en que había quedado y pronto se dejaban ver las posibilidades de que el acuerdo quedase cerrado, bien partiendo las diferencias, bien cediendo alguna de las partes en más de lo previsto inicialmente al imponerse otras razones y circunstancias, y fijando ya el momento en que sería retirada la mercancía y la forma de pago, a pie de camión una vez pesado o en determinados plazos. Cuando se llegaba al acuerdo, el corredor y el campesino se daban la mano en señal de conformidad y de asentimiento, que ya no podía ser alterado en ningún punto y quedando como prenda, en el mayor número de ocasiones, la palabra dada entre las partes.

Mientras duraba el trato estaba muy mal visto que un corredor que compraba para la competencia intentase entrar por medio para formalizar otro acuerdo, con las pretensiones de llevarse la operación al marcar para ello un sobreprecio del sobreentendido. Cuando esto ocurría y el trato primero se rompía, el corredor que se había visto desplazado no tardaba en dar las quejas y avisar que no le encontrarian cuando le necesitasen en el futuro, y el agricultor pasaba a ser considerado como una persona informal, por muy suyo que fuese el montón de cáscara, y puesto en entredicho por cuantos intervenían en este mercadeo y que se consideraban formales.

El lugar en que se celebraba el trato era por lo general la explanada abierta ante la puerta del caserío y de pie, mientras la mujer del campesino 
se asomaba intermitentemente o permanecía quieta en la puerta, medio cubierta por la persiana o un toldo de lona que protegía el interior del polvo, con la mirada en el suelo en tanto los hombres hablaban y hablaban desde sus posturas encontradas. De cuando en cuando, el campesino lanzaba miradas de consulta a su mujer; si permanecía silenciosa sin levantar la mirada, se debía de interpretar como que no debía de ceder en nada de lo propuesto, lo que venía a suceder el primer día, mientras que en el segundo, las consultas se hacían por parte del marido de palabra, al preguntarle qué te parece el precio que dice, a ti qué te parece, a lo que solía responder la mujer, cuando opinaba, que no se debía ceder en mayor cantidad, que si por ella fuese que no lo daría pues ella sabía muy bien el trabajo que habia costado hacer aquellos pocos kilos de cáscara. Cuando la mujer creía que ya se estaba en un precio aceptable, la respuesta, invariablemente, era: Eso tu verás, que eres el que decides.

En otras ocasiones, cuando el campesino no quería que apareciese su mujer por medio, el trato solía llevarse a cabo en el pueblo más cercano, quedando con el corredor en el bar, donde una vez sentados a una mesa, mientras los parroquianos y conocidos les observaban de lejos, trataban de la cosecha. Los dos hombres conducían la plática con vivos movimientos de brazos y manos dejando que alguna vez, cuando se cerraban en una postura, se levantasen un poco las voces. El apretón de manos marcaba el fin, que solía celebrarse con algunas bebidas que el corredor debía pagar, mientras que se rezaba aquello de Que sea para bien, que era como el aviso para que algún curioso se acercase a ellos. Después la mujer se quejaría diciéndo que ella se enteraba cuando las cosas estaban hechas.

En los años setenta, cuando se generalizó entre los campesinos la posesión de un automóvil, éstos, en muchas ocasiones, pidieron que la última parte del trato se celebrase en la fábrica del exportador, pues querian conocer la cara del que se iba a llevar su cáscara, lo que conllevaba que se concertase la visita a la fábrica, donde, si era la primera vez, se hacía antes un recorrido por las instalaciones de molinería, de extracción del aceite esencial del pimentón y del secadero (estas dos últimas cuando las había) en compañía del exportador, y así el agricultor podía observar y calcular el movimiento de mercancías. El campesino, antes, cuando había discutido el precio con el corredor, había preguntado si el industrial tenía palabra de rey, lo que por lo general parecía una imposición que no gustaba, por lo que éste, en esta segunda fase del trato, solía aparecer en un segundo plano mientras que eran el agricultor y el corredor los que intervenían en la discusión, ya más aparente que real; lo que daba ocasión a que el exportador, en determinado momento, entrase en el trato 
para proponer una cantidad que partía la diferencia, y que, en apariencia a regañadientes, aceptaba el agricultor.

Como vemos, en estas ocasiones el trato era completamente distinto; el tiempo aparecía medido de manera diferente al quedar muy limitado en la última fase, por lo que el acuerdo sobre el precio había quedado prácticamente fijado de antemano por el campesino y el corredor, a expensas de una pequeña diferencia que era la que se cedía como deferencia ante el industrial, y porque no diga de mi que no be querido venderle en la primera visita que hago a su casa.

Si queremos precisar el sentido del rito en sí mismo, no sólo como un medio, como han hecho numerosos antropólogos en otras tantas definiciones, deberemos tener presente en él una serie de rasgos que aparecen cacterizándolo como un convencionalismo formal que puede ser, como tal, admitido o no por los que lo practican; y que por ello conlleva una teatralidad que se sostiene sobre gestos y posturas preconcebidas (incluso sobre efectos especiales) ${ }^{3}$; que se practica siempre en un determinado momento, bien en el tiempo o motivado por unas circunstancias concurrentes; y que se presenta como una práctica manifiesta que aparentemente no contiene utilidad en sí misma, aunque es sumamente necesaria, bien porque se busque a través de ella una causa, próxima o remota, bien porque se practique como una realización imprescindible. Todo ello conduce a definir el rito como un medio que es una representación convencional, que implica una continuidad repetitiva, siempre repetitiva, en la que la menor novedad es invariablemente rechazada, por la que se transmite una información que se considera necesaria para que sucedan y cumplan determinados acontecimientos, y que, como tal, conlleva una comunicación entre el emisor y el receptor de un mensaje que puede incidir, como defendieron ciertos antropólogos funcionalistas como Radcliffe-Brown y Rappaport ${ }^{4}$, en un utilitarismo, en la difusión de determinada información que legitima valores sociales establecidos y aceptados, y que sirve, al mismo tiempo, para aminorar el estado de ansiedad que se ha adueñado de cuantos participan en él. Añadiríamos por nuestra parte, que también puede darse el caso en que esto no sea así y el

3 Sobre aspectos teatrales del rito ver Jean S. LA FONTAINE, Ritual drama and secret knowledge across the world (Harmondsworth, 1985). Utilizo edición española (Barcelona, 1987), pp. 265 y ss.

4 El concepto de rito de RADCLIFFE-BROWN se puede rastrear en obras como Taboo (Cambridge, 1939); Structure and function in primitive society (London, 1952); *Religion and society", Journal of the Royal Anthropological Institute, LXXX (1951). De R. RAPPAPORT, "Ritual regulation of environmental relations among a New Guinea peoplen, Ethnology, VI (1967); "Ritual, sanctity and cybernetic", American Antbropologist, LXXIII (1971). 
rito pueda ser definido sobre una valoración instrumental, aparte de su convencionalismo y representación, y de su aparición en ciertos momentos y circunstancias. En el rito, la transmisión de dicha información descansa sobre símbolos que, a diferencia del lenguaje, no necesitan ser descodificados o comprendidos por el receptor para completarse en su cerrado ciclo demostrativo y a la vez enigmático, ya que ello sucede en cuanto llega a ser y el que lo ejecuta y contempla lo admite como tal ritual, porque es un bien necesario en su forma, en su imagen, que se completa al desarrollarse, que conduce a que el propio rito pase a ser asumido con categoría de símbolo superior, existencial y arraigado, cuyo significado radica en su propia permanencia y presencia, en su propio desarrollo iterado, independientemente de que sirva para mostrar un orden social establecido, como podemos percibir en el rito que hemos descrito en páginas anteriores.

El rito es una representación que teatraliza la vida y que en muchas ocasiones ha sido contemplada vacía de significado, como encontramos con suma frecuencia en muchas fiestas y otras manifestaciones de la vida social, tanto en la Antigüedad como en nuestros días, lo que hace que el que participa en uno de ellos siempre o casi siempre desconozca su origen y el significado primigenio. Por otro lado, el acto que originó dicho ritual jamás llegó a ser un rito en sí mismo hasta que pasó a adquirir una nueva categoría al volver a hacerse de manera más o menos consciente una y otra vez, por mimetismo, dentro de lo que se entiende por tradición. Pero lo que no podemos olvidar, es que el rito es un convencionalismo que, ante todo, es explicativo de un comportamiento que guarda una intencionalidad de legitimación de un presente que ha de mostrarse como consolidado, lo que ha hecho que, desde la Antigüedad, muchos rituales, como los religiosos o festivos, sobre todo los concernientes a la magia e incluso algunos de la vida cotidiana, que trataban de cambiar el curso de la naturaleza a voluntad, hayan sido vistos como una acción de significado enigmático y secreto.

El rito, así, llegó a serlo, por iniciarse sobre él una repetición que lo tipificó como fórmula feliz y necesaria, y por ello en él hay, permanentemente, una recuperación de la memoria y un acto de negación de dicha memoria, lo que implica de forma manifiesta un acto de afirmación colectiva por el que se es y se fue a la misma vez, aunque, por otro lado, ello no conlleve una explicación justificativa del presente sobre el pasado. El rito, al final, es una actuación que alcanza su verdadero sentido al hacerse a sí mismo, al cumplimentarse.

En muchas ocasiones, en que el ritual aparece alejado de un claro significado inmediato, el observador que lo contempla - no que participa en él- o que participa desde la distancia no contaminante, frecuentemen- 
te, por un sentido historicista, trata de remontarse hasta el primer acto que lo motivó y del que procede, como si el rito fuese el caparazón de un contenido mítico del que quedó desprendido en determinado momento de su evolución, y que hay que buscar y encontrar para volver a acoplárselo, pues así se alcanzaría un conocimiento esencial y primigenio. Puede que ello sea acertado y como tal sirva para que los amantes de conocer el pasado, presuntamente explicativo, fijen en el devenir ordenado de los sucesos una cronología de los motivos que promovieron y desarrollaron la aparición de una fórmula magistral que después pudo rehacerse una y otra vez al ser aplicada a variantes, o a otros argumentos de valor igualmente temporal limitado y tornadizo. Pero el rito, si queremos llegar a saber de su valor, independientemente de continuar por esa vía que busca en el pasado, debemos contemplarlo en lo que es en el momento en que se produce, como un artificio formal o, si queremos, como una apariencia aceptada por sí misma y sobre la que se encauzan a veces actos de fe o determinados conocimientos, u otras razones de las que no se tiene conciencia, aunque admitiendo ante todo que como tal traza enmascara una tensión emocional de cuantos participan en él y que al mismo tiempo obra sobre una valoración del momento que se vive, que aparece de manera cíclica y que explica, sobre todo, la llegada de un ahora, que se actualiza como un enigma vivificador.

Por ello el rito puede ser visto, a grandes trazos, de dos maneras: Una si se tiene conciencia de que por él se reexperimenta un acto significativo del pasado, cercano o lejano, y como tal se verifica en el que lo cumple sobre un proceso de contemplación de sí mismo en ese pasado, con la consiguiente liberación de parte de lo que uno fue y continúa siendo y, en la parte recóndita de su conciencia, de parte de lo que sabe que también fue y todavía es. Esto conduce directamente a que el rito actúe a modo de catarsis, como supieron ver los psicoanalistas desde que el doctor Josef Breuer lo aplicó en 1880 y cuyo valor terapeútico empleó Freud y continuadores según un método que también se ritualizó en muchas de sus fases, y siempre dentro de un reduccionismo psicológico ${ }^{5}$. Y otra, si esa conciencia de reexperimentación falta en el rito desprendido del pasado, tal como suele hacer el hombre cuando cumple con el rito y por ello se afianza a sí mismo apoyándose en ese momento, en su presente, para vivirlo una vez más por primera vez.

5 La catarsis como ingrediente del rito, al analizar la importancia de las emociones en los comportamientos sociales, ha sido vista en una teoría, que es discutible en muchos aspectos, por T. J. SCHEFF, Catharsis in Haeling, Ritual, and Drama (Berkeley: University of California Press, 1977). Las observaciones de FREUD en Estudios sobre la bisteria. 
La primera clase de ritos, la vislumbramos, por ejemplo, con claridad en el que tiene efecto en el sacramento cristiano de la confesión. Aquí, determinados actos del pasado de cada hombre, desde la conciencia de culpabilidad, obran al rehacerse por el reconocimiento de su responsabilidad al haberlos cometido libremente y por ser expuestos de palabra ante otro hombre, un sacerdote - que permanece medio oculto y al que, posiblemente, no conoce-, que al final le absolverá o no en nombre de Dios de la falta cometida y reconocida, principalmente, ante él mismo en lo que es un acto radical de humildad, que, sin duda, actúa con efectos espirituales curativos. Lo que está y no debía de estar en el comportamiento del hombre, que sabe que debe apartarlo de sí, toma categoría de fundamento al situarlo delante de él mismo, porque la confesión, sobre todo, es un rito personal, independientemente que se lleve a cabo ante otra persona. El pasado se hace presente para liberarse de él, para que la conciencia de su presencia, torturadora, desaparezca por un acto de voluntad al emplazarlo delante y no por el olvido que se pueda producir con el paso del tiempo.

En la segunda clase de ritos podemos situar muchas de las fiestas, antiguas y modernas, entre las que destaca el Carnaval, sin duda alguna la manifestación festiva más importante, que viene a ser un ritual que se fundamenta en una transgresión del rito de la vida cotidiana. Como tal, tiene una evolución en el tiempo desde que aparece como heredera de otras fiestas de la Antigüedad -que posiblemente reflejaban, por mimetismo, el caos que se obraba en la naturaleza por la falta de conjunción entre el año lunar y el año solar ${ }^{6}$ - y, tras ser perseguida con ahínco y fijeza por el cristianismo en los primeros siglos, fue reducida a unos actos, a veces misteriosos, en los tres días anteriores a la entrada de la Cuaresma, como la espita que deja libres las tensiones que se han ido acumulando en el día a día del resto del año.

Pero en esta segunda clase de ritos, donde se alcanza su valor como tal rito por hacerse en un presente insalvable, adquiere la categoría de ser principio y fin del paso del tiempo, del paso de la vida. Hasta el año que viene dicen siempre los que participan en un rito festivo cuando este acaba; hasta que nos volvamos a ver dicen los que cumplen con el rito de despedida...

También, independientemente de lo apuntado, el rito puede ser visto desde dos perspectivas bien diferentes entre sí: desde la que lo entiende como el medio acabado para que se formalicen las funciones sociales sobre las que se desarrolla la vida de una comunidad. En él, el individuo,

6 Francisco J. Flores Arroyuelo, Fiestas de pueblo (Murcia, 1990), pp. 103 y ss. 
como defendía Durkheim, se siente colmado de una energía que es colectiva y de la que participa porque es miembro, lo que llevó a este autor a defender la hipótesis de que las prácticas rituales contribuían a la representación de las estructuras que apoyaban a una sociedad y, también, que dichos ritos cumplían la función de reflejar en la conciencia de los hombres, comprendidos individualmente, la imagen que la sociedad que les albergaba tenía de la realidad de que formaba parte ${ }^{7}$. Junto a Durkheim, encontramos a otros autores como Radcliffe-Brown, EvansPritchard, Fortes, Firth, Leach, Middleton... ${ }^{8}$, que, con una gran diversidad de matices, han defendido que el rito existe siempre para que se sostenga y consolide la serie de valores que, en sistema ordenado, tienen todas las sociedades y que hacen posible su existencia como tales.

También, dentro de la corriente que defiende la presencia de las emociones en la formación del rito -e independientemente de lo que apuntan Freud y otros psicoanalistas al analizar los síntomas obsesivos, y por ello repetitivos, como su fundamento- podemos señalar lo que Malinowski dijo cuando desarrolló la idea de que los ritos aminoran la tensión y la angustia que a veces se apoderan de las sociedades cuando sienten miedo, porque sobre ellas se ciernen amenazas de calamidades naturales como plagas, epidemias, etc., que hacen que el futuro se presente colmado de incertidumbre ${ }^{9}$. En la misma línea podemos situar a Beattie, Geertz ${ }^{10}$, y otros, con teorías sumamente complejas, como la defendida por Scheff en el trabajo antes citado, donde el rito aparece desde una institucionalización de la emoción al actuar produciendo unos determinados efectos liberadores.

7 Sobre los ritos positivos ver E. DURKHeIM, Las formas elementales de la vida religiosa (Madrid, 1982), pp. 303 y ss.

8 Aparte de las obras citadas de Radcliffe-Brown, ver de E. E. Evans-PRITCHARD, Withcraft, oracles and magic among the Azande (London, 1937); Nuers religion (Oxford, 1956). De FORTES, Oedipus and Job in West African religion (Cambridge, 1959). De R. FIRTH, The work of the gods in Tikopia (London, 1940); Tikopia ritual and belief (London, 1967); Essays on social organization and values (London, 1964). De E. LEACH, "Ritualization in man in correlation to conceptual and social development", J. HUXLEY (ed.), Ritualization of behavior in animals and man, en Philosophical Transactions of the Royal Society of London, vol. 251, núm. 772 (1966); Culture and Communication: The Logic by which Symbols Are Connectd (Cambridge, 1976). De J. MIDDLETON, Lugbara religion (London, 1960).

9 B. MALINOwSKI, Myth in primitive psychology (London, 1926); Magic, science and religion and other essays (Blencoe, 1948).

10 Ver de J. Beattie, "The ghost cult in Bunyoro", Etbnology, III, 2 (1964) y de C. GEERTZ, "Religion as a Cultural System", M. BANTON (ed.), Anthropological approaches to the study of religion (London, 1965). 
Sin duda alguna, en el rito, en la práctica del rito, se establece una jerarquización de la sociedad, al hacer que cada uno de los miembros que la componen aparezca situado en su lugar, con lo que el orden social, conforme se desarrolla su práctica, queda consolidado. Pero igualmente cierto es que todo rito conlleva un factor emocional que implica que todo hombre que participa en él adquiera una certidumbre de que al llevarlo a cabo, al cumplirlo, termina una fase que, a su vez, es necesario que quede cerrada y así se pueda iniciar la siguiente. Esto hace que el rito, como rito, como instrumento eficaz que limita los cambios que impone el devenir del tiempo en la naturaleza, en el individuo y en la vida social, tenga una consistencia temporal de presente que lo hace válido por sí mismo, hasta el punto de ser una necesidad manifiesta en el quehacer del hombre, lo que nos conduce, al mismo tiempo que así lo comprendemos, a poder contemplarlo como un paso entre una fase que se termina y otra que comienza.

Cuando Van Gennep analizó diversos ritos dentro de un gran marco que calificó de paso, y sobre ellos elaboró una fecunda tesis, sobre todo, se fundamentó en el carácter de temporalidad que muchos ritos contenían, al adaptarse a las fases del día, de la semana, del año... y hasta de la misma vida humana, por lo que prestó una gran atención a los ritos de iniciación, en los que un antes y un después quedaban bien manifiestos ${ }^{11}$.

Por nuestra parte, al referirnos al ritual observado en el trato de compra-venta de cáscara de pimiento en el campo murciano, debemos distinguir una serie de elementos que podemos clasificar del siguiente modo:

A) El rito sucede al final del largo proceso de producción agraria.

B) El resultado de dicho ritual sirve, en primer lugar, para dar valor al producto, lo que es lo mismo que decir al trabajo de nueve meses con preparación de tierra, abonados riegos, fumigaciones... y otros finales en los que aparece un riesgo adicional que puede llevar a que todo quede perdido o reducido en buena proporción.

C) La duración del tiempo en la exposición de las razones que fundamentan las posturas, insistiendo en un precio de compra por parte del intermediario y resistiendo en la aceptación en la opuesta por parte del agricultor, es celosamente observada, dando así, aparte del valor pecuniario, una manifiesta consideración a la mercadería y al trabajo que lo ha hecho posible, y, en último término, una categoría manifiesta al productor.

D) Hay una gradación en importancia de las personas que intervienen en el rito: en primer lugar está el industrial o exportador que permanece

\footnotetext{
11 Arnold van GenNeP, Los ritos de paso (Madrid, 1986) (1. ${ }^{2}$ en París, 1909).
} 
retirado, en segundo está el agricultor que defiende su producto sobre un precio, y en tercer lugar está el intermediario que sólo sale beneficiado, y por tanto ve remunerado su trabajo, si el trato de compra-venta llega a buen término.

E) Con la consumación del rito se finaliza un tiempo, la temporada terminada, y se da comienzo a otro que en ese mismo momento se inicia, la nueva temporada.

F) Por el rito, el agricultor ve una ocasión de sobresalir entre sus vecinos, bien porque consigue por su arte alcanzar un precio mayor, bien porque se ha decidido a vender en el momento óptimo de lo que puede ser el alza del precio del producto.

G) Y por último está la presencia de la palabra dada que sella el acuerdo con el apretón de manos correspondiente, con lo que ésta adquiere una categoría de fijeza que da sentido a todo el rito. Una vez empeñada, esa palabra es sagrada, te hayas equivocado o se hayan equivocado ${ }^{12}$.

En este ritual también hay un factor emocional que debemos tener en cuenta, y que se manifiesta en la sostenida tensión que lo hace posible, al intervenir como un factor importante a la hora de establecer el valor del resultado de un trabajo y de las posibilidades existentes para que se pueda conseguir una comercialización remuneradora. La asistencia de las tres partes, en sus diferentes cometidos, a lo largo de la acción, marca al final una liberación en el agricultor y una entrada en el desarrollo de la aventura comercial por parte del industrial y también, aunque en menor grado, en el corredor.

Independientemente de las partes enfrentadas, de una que permanece oculta mientras dura todo el proceso ritual, y de otra que está siempre presente, y de una tercera que actúa como diestro oficiante capaz de que el objeto que se persigue con la práctica del ritual llegue a feliz término, debemos considerar que estos tres elementos, que desde planos diferentes actúan enfrentados y unidos coyunturalmente, nos están mostrando que el

12 Los corredores o intermediarios son unos hombres que tienen una relación comercial establecida sobre la palabra dada por ambas partes. Como tales tenían que ir y venir entre compradores y vendedores hasta que se llevaba a buen fin el trato, dando lugar al contrato que se sostenía sobre esa palabra, que actuaba a modo de ligadura, o se rompía quedando las partes libres para actuar. En Roma estos hombres que hacían de intermediarios fueron llamados Fidus, que en español dio fedatarios, porque daban buena fe en su palabra. En España se utilizó el término de corredor derivado de corretier, por ir y venir corriendo con la palabra entre varios hombres que buscaban un entendimiento, lo que hizo que ya en el siglo XVI se usase también en sentido de alcabuete, como encontramos en el Guzmán de Alfarache. Ver COROMINAS, Diccionario Crítico Etimológico, voz *Corretaje*. 
rito -como expusieron en sus teorías M. Gluckman y E. Norbeck ${ }^{13}$, bien alejadas de las posturas funcionalistas, e incluso de las de Firth y Leach ${ }^{14}$ sirve para evidenciar las diferencias sociales existentes en una comunidad, y para que de este modo, por él, se puedan encauzar de modo distendido, evitándose las posibles disputas y enfrentamientos a que podrían dar lugar al presentar a las partes, claramente diferenciadas (el industrial y el campesino) y hasta socialmente jerarquizadas, en un plano de igualdad, dentro de lo que es una representación que aglutina unas complejas relaciones, ampliadas por hacerse de modo indirecto. Esta característica, a su vez, podría aproximar este proceso ritual a aquellos otros en los que la inversión de papeles se produce, como las fiestas, por ejemplo, en las que el amo sirve durante un día al criado, y en otras muchas.

El rito vendría a ser también una actuación convencional y como tal sería aceptada. Por ella se mitigarían y hasta disfrazarían las posibilidades de un conflicto, de una oposición, de una hostilidad encubierta, fiel reflejo de las diferencias que existen en la sociedad, y por tanto sería cauce regulador de latentes aspectos diferenciales. Lo que hace, al final, que este rito pueda ser comprendido junto a aquellos que tienen la finalidad de mantener el orden para así llegar a resolver una serie de conflictos latentes y contradicciones que están presentes en los diferentes principios sobre los que se organiza una sociedad.

Las tres partes, posiblemente desde un principio, saben el precio que se va a terminar aceptando en el trato; el único que es posible, que es el que viene dado por el mercado según la ley de la oferta y la demanda, salvo incidencias que particularicen la materia prima como una manifiesta mejora en la calidad o una clara tara. Pero también, todos ellos saben que para llegar a él deberán andar juntos, y desde sus puestos respectivos, el camino que marca el ritual, para que así cada una de las partes quede consolidada en su respectiva postura. No hay peor venta de un producto que se ha conseguido con esfuerzo que la que se hace sin pelear su precio, su valor, dicen los agricultores, a lo que añaden, ya que es como si lo regalaras. Lo mismo sucede, aunque de manera más prosaica, dada la clase de dinámica en que está inmerso, en el industrial cuyo esfuerzo aparece sobrecargado en la figura del corredor, que al final siempre ter-

13 M. Gluckman, "Introducción", Essays on the Ritual of Social Relations (Manchester, 1962); y Politics, law and ritual in tribal society (Oxford, 1965) De E. NoRBECK, Religion in primitive society (New York, 1961); "African ritual of conflict", American Anthropologist, LXV, 6 (1963).

it De R. FIRTH ver Essays on social organization and values (London, 1964), African political systems (London, 1940); Symbols, Public and Private (London, 1973) y de LEACH ver trabajo citado, supra nota 8. 
mina actuando como un permanente doble suyo, como una máscara, pues al día siguiente, o en otro lugar en aquel mismo día, actúa nuevamente representándole, y como tal vuelve a repetir el mismo ritual.

El rito, como decíamos al principio, es una representación, una puesta en escena, que en muchas ocasiones sólo tiene significado en sí misma, convirtiéndose en caparazón vacío, en caparazón desmitificado. Pero en otras, el rito es algo completamente diferente, como en el caso que hemos expuesto, ya que si llega a existir como tal es precisamente porque su significado descansa como un concierto añadido en un elemento tan fluctuante y difícil de precisar como es el valor de una cosa concreta, y por ello llega a ser el medio que posibilita que éste consiga fijarse, a hacerse realidad para siempre ${ }^{15}$.

\section{FRANCISCO J. FlORES ARROYUELO \\ Universidad de Murcia}

Se analiza el ritual de la compra-venta del pimentón en Murcia. Este cultivo, procedente de América, es implantado en el $s$. Xvil por los monjes jerónimos en el poblado de La Ñora, extendiéndose por la huerta del Segura en el s. XviII y llegando como cultivo tradicional hasta el xx. La demanda masiva hacia Estados Unidos en los años cincuenta alteró, no sólo el sistema de cultivo, sino las complicadas relaciones -como una puesta en escena- entre comprador y vendedor, desde que se iniciaba el trato hasta que quedaba cerrado.

This article is concerned with the red pepper trade rituals in Murcia. The cultivation of this originally American product was introduced in the seventeenth century by Hieronymite monkds in La Nora, a small village located within the farming area surrounding the river Segura. The traditional farming of red pepper has lasted till this century. The very high demand of this product from the United States since the fifties has modified not only the cultivation system, but also the complex "mis en scene. performed by the buyer and seller during the deal.

15 Comunicantes: Alejandro Menarguez, «Modesto», de la pedanía El Raal (Murcia), corredor. Antonio Nortes Macanás, "El Caheten, en Espinardo. Francisco Legaz Jiménez, Los Leones, Fuente Álamo (Campo de Cartagena). José García García, *El Forca•, Monteagudo. Juan Pagán «El de los Paganes", Totana. 